\title{
SYNTHESIS OF SULFUR-BASED WATER TREATMENT AGENT FROM SULFUR DIOXIDE WASTE STREAMS
}

\author{
Annual Technical Progress Report \\ Reporting Period Start Date: September 1, 2000 \\ Reporting Period End Date: August 31, 2001 \\ Principal Author(s): \\ Robert C. Brown and Maohong Fan
}

Date Report Issued:

December, 2001

DOE Award Number:

DE-FG26-00NT40812

Submitted By:

Center for Sustainable Environmental Technologies

Iowa State University

285 Metals Development Bldg.

Ames, IA 50011-3020 


\section{DISCLAIMER}

This report was prepared as an account of work sponsored by an agency of the United States Government. Neither the United States Government nor any agency thereof, nor any of their employees, makes any warranty, express of implied, or assumes any legal liability or responsibility for the accuracy, completeness, or usefulness of any information, apparatus, product, or process disclosed, or represents that its use would not infringe privately owned rights. Reference herein to any specific commercial product, process, or service by trade name, trademark, manufacturer, or otherwise does not necessarily constitute or imply its endorsement, recommendation, or favoring by the United States Government or any agency thereof. The views and opinions of authors expressed herein do not necessarily state or reflect those of the United States Government or any agency thereof. 


\begin{abstract}
We propose a process that uses sulfur dioxide from coal combustion as a raw material to synthesize polymeric ferric sulfate (PFS), a water treatment agent. The process uses sodium chlorate as an oxidant and ferrous sulfate as an absorbent. The major chemical mechanisms in this reaction system include oxidation, hydrolysis, and polymerization. Oxidation determines sulfur conversion efficiency while hydrolysis and polymerization control the quality of product. Many factors, including $\mathrm{SO}_{2}$ inlet concentration, flow rate of simulated flue gas, reaction temperature, addition rate of oxidant and stirring rate, may affect the efficiencies of $\mathrm{SO}_{2}$ removal. Currently, the effects of $\mathrm{SO}_{2}$ inlet concentration, the flow rate of simulated flue gas and addition rate of flue gas on removal efficiencies of $\mathrm{SO}_{2}$, are being investigated. Experiments shown in this report have demonstrated that the conversion efficiencies of sulfur dioxide with ferrous sulfate as an absorbent are in the range of 60-80\% under the adopted process conditions. However, the conversion efficiency of sulfur dioxide may be improved by optimizing reaction conditions to be investigated. Partial quality indices of the synthesized products, including $\mathrm{Fe}^{2+}$ concentration and total iron concentration, have been evaluated.
\end{abstract}

Keywords: sulfur removal, flue gas cleanup, air pollution, polymeric ferric sulfate. 


\section{TABLE OF CONTENTS}

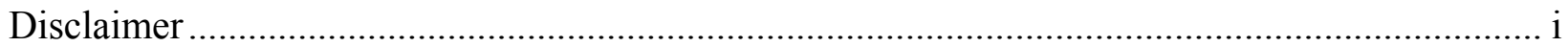

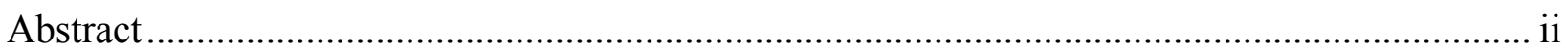

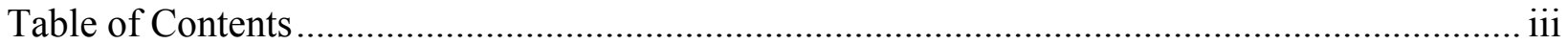

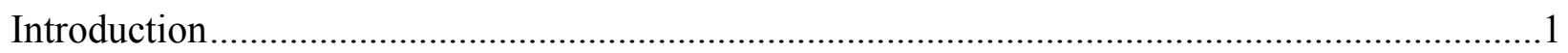

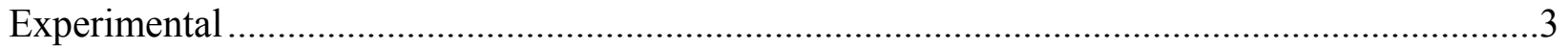

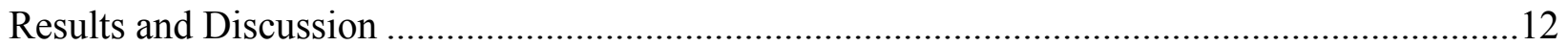

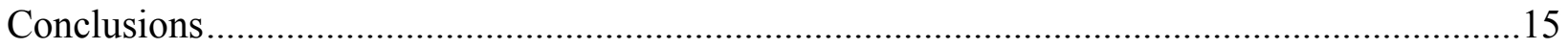

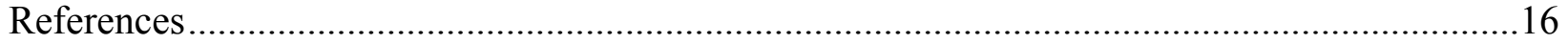

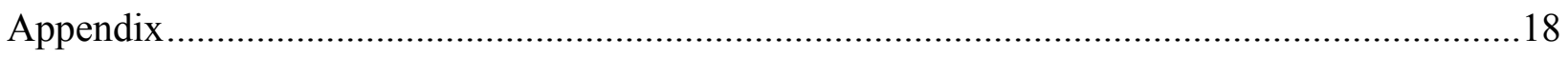




\section{INTRODUCTION}

Using ferrous sulfate and sulfuric acid as the major raw materials, we have invented a new method for synthesizing PFS [1-2] and this technique has been commercialized in industry. This technique overcomes several problems with conventional PFS synthesis process [3-4], the most important of these being the production of potentially carcinogenic nitrite in the product and relatively large capital and operating cost of the system.

The toxicity and coagulation performance evaluations of PFS synthesized by the new technique [1-2] have been conducted in the United States. The toxicity evaluation experimental results have demonstrated that there is no evidence showing that the PFS synthesis technique has led to any health problem [5]. The coagulation performance tests have shown that PFS produced from ferrous sulfate, sulfuric acid and sodium chlorate, is superior to the traditional coagulants in turbidity removal ability under different conditions [2]. These results are very supportive for dramatically expanding PFS applications in drinking and wastewater industries in the near future all over the world.

The conversion of coal to electricity generates vast quantities of acid gas-laden waste streams [6-9], either as gas emitted to the atmosphere or as sludge salts that are typically land filled. The use of limestone for removing acid gases generates additional greenhouse- $\mathrm{CO}_{2}$ due to lime production. Industrial ecology principles mandate the conversion of these acid gases into high-value products for market. Unfortunately, commodity products such as sulfuric acid made from sulfur dioxide have insufficient market value to encourage new capital investment for their

production. Therefore, alternative approaches to utilization of sulfur dioxide in flue gas need to be searched. 
We propose the production of polymeric ferric sulfate (PFS) from sulfur dioxide. PFS is a flocculating agent that has been adopted for water treatment in many parts of the world even it is being widely used in the United States because of public health concerns about aluminumbased flocculating agents. Some medical studies implicate aluminum as an agent in the development of Alzheimer's disease [10-11]. Environmental exposure to aluminum can take many forms during a lifetime, but of particular concern is the relatively large cumulative dosage arising from aluminum salts in drinking water supplies. Ironically, these salts are intentionally added to drinking water as part of water purification measures. Aluminum salts have long been considered a benign flocculating agent to clarify drinking water. A growing number of public health experts and environmentalists are encouraging alternative physicochemical treatments of drinking water to replace common aluminum-based flocculants such as polymeric aluminum chloride (PAC).

PFS, chemically described by the formula $\left[\mathrm{Fe}_{2}(\mathrm{OH})_{\mathrm{n}}\left(\mathrm{SO}_{4}\right)_{(6-n) / 2}\right]_{\mathrm{m}}$ where $\mathrm{m}$ is a function of $\mathrm{n}$, is a promising substitute for PAC. Foremost of its advantages is the absence of aluminum in its formulation. Other advantages include the fact that PFS can be used to treat lowtemperature and low-turbidity drinking water, which PAC has difficulty treating. Furthermore, PFS is more effective at reducing chemical oxygen demand (COD) than is PAC, especially when algal concentration in the water is high.

The major reactions of synthesizing PFS from $\mathrm{SO}_{2}$ are:

$$
\begin{aligned}
& \mathrm{NaClO}_{3}+3 \mathrm{H}_{2} \mathrm{O}+3 \mathrm{SO}_{2} \rightarrow 3 \mathrm{SO}_{4}^{2-}+6 \mathrm{H}^{+}+\mathrm{Na}^{+}+\mathrm{Cl}^{-} \\
& \mathrm{NaClO}_{3}+6 \mathrm{H}^{+}+6 \mathrm{Fe}^{2+}+6 e \rightarrow 3 \mathrm{H}_{2} \mathrm{O}+6 \mathrm{Fe}^{3+}+\mathrm{Na}^{+}+\mathrm{Cl}^{-}
\end{aligned}
$$

Oxidation of $\mathrm{SO}_{2}$ to $\mathrm{SO}_{4}^{2-}$ and $\mathrm{Fe}^{2+}$ to $\mathrm{Fe}^{3+}$ are followed by hydrolysis and polymerization, which are described by the sequences: 


$$
\begin{aligned}
& \mathrm{H}_{2} \mathrm{O} \Leftrightarrow \mathrm{H}^{+}+\mathrm{OH}^{-} \\
& 2 \mathrm{Fe}^{3+}+\frac{6-\mathrm{n}}{2}\left(\mathrm{SO}_{4}^{2-}\right)+\mathrm{n}\left(\mathrm{OH}^{-}\right) \rightarrow\left[\mathrm{Fe}_{2}(\mathrm{OH})_{\mathrm{n}}\left(\mathrm{SO}_{4}\right)_{\frac{6-\mathrm{n}}{2}}\right] \\
& \mathrm{M}\left[\mathrm{Fe}_{2}(\mathrm{OH})_{\mathrm{n}}\left(\mathrm{SO}_{4}\right)_{\frac{6-\mathrm{n}}{2}}\right] \stackrel{\left[\mathrm{H}^{+}\right], \text {additive } \mathrm{C}}{\longrightarrow}\left[\mathrm{Fe}_{2}(\mathrm{OH})_{\mathrm{n}}\left(\mathrm{SO}_{4}\right)_{\frac{6-\mathrm{n}}{2}}\right] \mathrm{M}
\end{aligned}
$$

Where $\left[\mathrm{H}^{+}\right]$is the concentration of added hydrogen ion and $\mathrm{c}$ is a polymerization promoter and $\mathrm{m}$ is the degree of polymerization.

The synthesis of $\mathrm{SO}_{2}$ into PFS offers the prospect of sulfur byproducts more valuable than the sulfuric acid conventionally produced from gas stream cleanup, as well as potentially significant improvements in public health. However, several issues must be resolved before this technology becomes a reality. The mechanism of inorganic polymerization and the reaction kinetics are still being studied so that production processes can be optimized. Quality indices are empirical in nature and have not been related to the polymeric structure of PFS. Drying, the final step in production of PFS, is known to greatly affect the amorphous structure of the inorganic polymer but is not yet fully understood. These questions and others are being examined in this research.

\section{EXPERIMENTAL}

\section{PFS Synthesis}

\section{$\underline{\text { Apparatus }}$}

The reaction system consists in general of three parts: flue gas simulation unit, reaction system and analysis of $\mathrm{SO}_{2}$ concentration in the simulated flue gas or treated emitted flue gas. A schematic diagram of the system is shown in Figure 1.

The entire system is contained in a fume hood, except for the nitrogen and air tanks, and the gas analyzer and its data system. Nitrogen and sulfur dioxide gasses are regulated from 
cylinder pressure down to $10 \mathrm{psig}$, and pass through rotameters to adjust their respective flow rates. They are then blended in a y-connector before entering the reactor via one or more sparge tubes immersed in the reaction solution. The reactor itself is a 41 jacketed glass vessel with a five-port lid. A peristaltic pump adds the sodium chlorate oxidant solution through a drip tube in the top of the reactor at a controlled rate. The mixture in the reactor is stirred at $180-200 \mathrm{rpm}$ by an immersed impeller connected to an adjustable motor above the reactor. A constant temperature is maintained in the reactor by a Neslab Model RTE-111 temperature bath unit with an integrated controller that circulates silicone bath oil through the jacket of the reactor.

The resulting gas mixture leaves the reactor through a condenser attached to the top, which is maintained at approximately $2{ }^{\circ} \mathrm{C}$ by a CETAC Model 2050 water chiller. The partially-dried gas is then routed through a concentric polymer membrane dryer tube and into the Fuji Electric Co. Model ZRF $\mathrm{SO}_{2}$ gas analyzer, with a bleed stream splitting off to vent flow in excess of the analyzer requirements. The drying tube transfers the moisture in the sample stream to an air stream flowing countercurrent on the other side of the membrane. The vent stream to analyzer stream flow ratio is controlled by a set of rotameters, as depicted in the Figure 1. The $\mathrm{SO}_{2}$ analyzer uses infrared light to measure the $\mathrm{SO}_{2}$ concentration in the gas stream, and displays the concentration in percent by volume on its front panel. It also generates a low-voltage DC signal that is sampled by a data acquisition board, converted to a digital value, and recorded by a desktop computer for later analysis. The reaction system used in this research was devised and assembled essentially from scratch, so considerable time was spent acquiring the necessary equipment and supplies and then assembling everything into proper working order. 


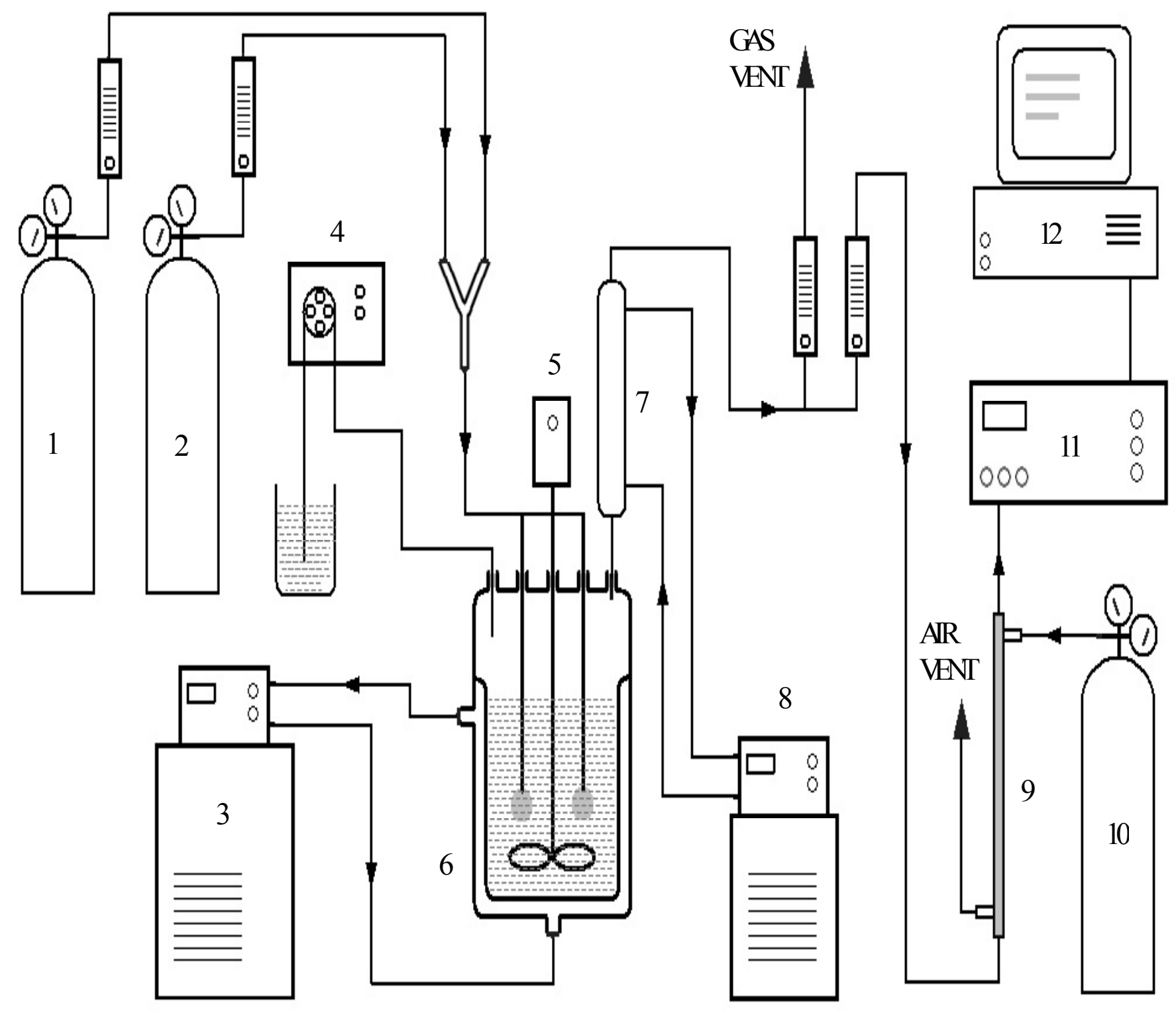

1. NITROGEN TANK

2. SULFUR DIOXIDE TANK

3. REACTOR HEATER UNIT

4. OXIDIZER PUMP

5. STIRRER MOTOR

6. JACKETED REACTION VESSEL
7. CONDENSER

8. CONDENSER CHILLER UNIT

9. SAMPLE GAS DRYER

10. AIR TANK (DRYER PURGE)

11. SULFUR DIOXIDE ANALYZER

12. DATA ACQUISITION COMPUTER

Fig. 1. Experimental apparatus for polymeric ferric sulfate (PFS) synthesis from $\mathrm{SO}_{2}$. 
Central to this reaction system is the sulfur dioxide gas analyzer. It is used to fine-tune the inlet concentrations used in the experiments, as well as to track the progress and efficiency of the reaction by monitoring the outlet gas stream. Many vendors were consulted, and the costs were found to be above the budget allotted for this piece of equipment. Finally, a supplier was found that was willing to negotiate, and an instrument was specially ordered from Fuji Electric Co. in Japan. Unfortunately, the lead-time was several months, which delayed the research progress to some extent.

After the $\mathrm{SO}_{2}$ analyzer arrived, testing and calibration of the system began immediately, and it was discovered that a simple liquid trap was not sufficient to prevent moisture from escaping the reactor. Moisture was condensing in the rotameters and believed to be causing interference with readings as sulfur dioxide was absorbing and desorbing from the liquid condensate in the tubing. It was decided to add a condenser to the system, which removes a good deal of the moisture, although additional improvements are still being engineered.

Another issue that continues to cause problems is plugging of the fritted sparge tubes used to disperse the simulated flue gas into the reactor. This occurs intermittently between similar reaction conditions. Investigation as to the cause and how to prevent it are still underway.

\section{Reagents}

Preliminary testing has been done with three types of ferrous sulfate: Mallinckrodt granular ferrous sulfate heptahydrate, analytical reagent; QC ferrous sulfate heptahydrate, agricultural grade; QC ferrous sulfate monohydrate, agricultural grade. The sodium chlorate used in the reaction is Fisher certified sodium chlorate. The sulfur dioxide gas (anhydrous, 99.98\%) used in tests was purchased from Matheson Trigas, Inc. 


\section{Operational Procedures}

The first step is to add ferrous sulfate and measured amount of water into the reactor, and close the top. Then the mixture in the reactor is stirred at $200 \mathrm{rpm}$ and allowed to equilibrate to temperature for 1-2 hours to ensure suspension and dissolution of the ferrous sulfate. A glass sparge tube is then immersed into the mixture, and the simulated flue gas consisting of a different proportion of nitrogen and sulfur dioxide gasses is bubbled up through the stirred

solution. Sodium chlorate oxidant is dosed periodically via the peristaltic pump and timer. A copy of the standard operating procedures for this system has been attached in the Appendix.

Reaction variables include reaction temperature, flow rate of simulated flue gas, sulfur dioxide concentration of simulated flue gas, stirring rate, and addition rate of sodium chlorate. A suitable test matrix is being developed to optimize the reaction conditions.

\section{$\underline{\text { Trials }}$}

Trials were conducted in batches, typically of a size to produce approximately $2 \mathrm{~kg}$ of finished PFS. The amount of each reagent used was calculated using the stoichiometry of the reactions as presented in the introduction section. Calculations have shown that production of a standard $2 \mathrm{~kg}$ PFS need $620 \mathrm{~g}$ monohydrate ferrous sulfate, $127 \mathrm{~g}$ sodium chlorate, $1139 \mathrm{~g}$ water, and $114 \mathrm{~g}$ sulfur dioxide gas. Typical reaction durations were 4-12 hours.

\section{PFS Quality Evaluation}

So far, in the United States, no PFS quality standard has been issued. A Chinese PFS [12] standard has been modified and used in this research. 


\section{Quality Indices}

The liquid PFS product quality is evaluated through the use of five analytical parameters, summarized in Table 1. The first quality index is a requirement that $\mathrm{pH}$ in a $1 \mathrm{wt}-\%$ PFS solution should be in the range of 2 to 3 . This is important because this value relates to PFS stability in storage and its application range. PFS with higher $\mathrm{pH}$ values makes it unstable in storage; ferric hydroxide tends to precipitate under these conditions. Furthermore, at higher $\mathrm{pH}$, PFS is less effective in the treatment of alkaline conditions, which are commonly encountered in industrial wastewater. Sulfuric acid can be used to control pH during PFS synthesis.

Table 1. PFS Quality Indices.

\begin{tabular}{|c|c|c|c|c|c|}
\hline Index & $\mathrm{pH}^{*}$ & $\begin{array}{c}\text { Total iron } \\
(\mathrm{wt}-\%)\end{array}$ & $\begin{array}{c}\text { Reducing** } \\
\text { Ions }(\mathrm{wt}-\%)\end{array}$ & $\begin{array}{c}\text { Density } \\
\left({\left.\mathrm{g} . \mathrm{cm}^{-3}\right)}^{-3}\right.\end{array}$ & $\begin{array}{c}\text { Basicity*** } \\
(\%)\end{array}$ \\
\hline Value & $2-3$ & $\geq 10$ & $<0.1$ & $\geq 1.4$ & $\geq 10$ \\
\hline
\end{tabular}

* this is the value of $1 \mathrm{wt}-\%$ PFS liquid.

** reducing ions are calculated in term of ferrous ion concentration.

*** this concept or called B value will be defined and explained later.

The second quality index is minimum concentration of iron in the liquid PFS product. High concentrations of iron in liquid PFS are desirable to reduce the cost of water treatment. However, too much iron in PFS makes it difficult to achieve another quality index, basicity, described subsequently. Iron concentration in PFS can be controlled by the amount of ferrous sulfate added during the synthesis process. Reduction-oxidation titration using titanous trichloride-potassium dichromate is presently used to determine this index.

The third quality index is the amount of reducing ions remaining in the PFS product, generally calculated in terms of $\mathrm{Fe}^{2+}$. However, we hope to entirely eliminate $\mathrm{Fe}^{2+}$ from the PFS product, since it is difficult to precipitate from treated water and contributes to undesirable coloration of water. We expect to achieve this goal by increasing the temperature of reaction and 
the amount of oxidant employed. This index can be chemically analyzed with the potassium permanganate titration method or by atomic absorption spectrometric procedure.

The fourth index is the density of liquid PFS, which should be higher than $1.4 \mathrm{~g} / \mathrm{cm}^{3}$. This is a physical indicator of total iron concentration in the PFS. Generally speaking, if the total iron concentration of PFS is higher than $10.5 \mathrm{wt}-\%$, this condition will be met.

The fifth quality index is the most important one: the basicity of PFS should be equal to or greater than $11.0 \mathrm{wt}-\%$. According to conventional wisdom, basicity should represent the degree of polymerization of PFS. However, very little fundamental study of these new inorganic polymers has been performed to confirm this belief. Nevertheless, large values of basicity indicate that the values for $\mathrm{n}$ and $\mathrm{m}$ in the formula for PFS, $\left[\mathrm{Fe}_{2}(\mathrm{OH})_{\mathrm{n}}\left(\mathrm{SO}_{4}\right)_{(6-n) / 2}\right]_{\mathrm{m}}$, are large. Basicity is correlated to increased precipitation of vitriol during water treatment and improved efficiency of pollutant removal. Moreover, high basicity of PFS is preferable for treatment of acidic wastewater. Generally, high basicity can be achieved through adjustment of several process conditions.

\section{Quality Tests}

\section{Determination of Density}

About $100 \mathrm{ml}$ crude PFS is added to a $100 \mathrm{ml}$ beaker, which is then placed in a water bath controlled at $20^{\circ} \mathrm{C}$. The density of the liquid is then determined by inserting density meter.

\section{Determination of Total Iron Concentration}

To determine the total iron concentration of the prepared PFS, the PFS solution is first acidified with hydrochloric acid, and then most of the ferric iron is reduced to ferrous iron by the addition of stannous chloride. The remainder is reduced by the addition of titanous trichloride [13]. The resulting solution of ferrous $\left(\mathrm{Fe}^{2+}\right)$ ions is then titrated with a standard potassium 
dichromate solution to measure the total iron concentration. The sequence of chemical reactions is shown below:

$$
\begin{aligned}
& 2 \mathrm{Fe}^{3+}+\mathrm{Sn}^{2+}=2 \mathrm{Fe}^{2+}+\mathrm{Sn}^{4+} \\
& 2 \mathrm{Fe}^{3+}+\mathrm{Ti}^{3+}=2 \mathrm{Fe}^{2+}+\mathrm{Ti}^{4+} \\
& 6 \mathrm{Fe}^{2+}+\mathrm{Cr}_{2} \mathrm{O}_{7}^{2-}+14 \mathrm{H}^{+}=6 \mathrm{Fe}^{3+}+2 \mathrm{Cr}^{3+}+7 \mathrm{H}_{2} \mathrm{O}
\end{aligned}
$$

The total iron concentration (wt-\%) is determined with the following expression:

$$
\mathrm{X}_{1}=\frac{\mathrm{V} \times \mathrm{C} \times 0.05585 \times 6}{\mathrm{~m}} \times 100
$$

where $\mathrm{X}_{1}$ is the total iron concentration (wt- $\left.\%\right)$ in the PFS, V is the volume (ml) of potassium dichromate standard solution consumed at the end point, $\mathrm{C}$ is the concentration (M) of the standard potassium dichromate solution, $\mathrm{m}$ is the mass ( $\mathrm{g}$ ) of the sample of the PFS, and 0.05585 is the mass $(\mathrm{g})$ of 0.001 mole iron.

\section{Determination of $\mathrm{Fe}^{2+}$ Concentration}

A potassium permanganate titration method is used to determine the ferrous iron concentration in the PFS. The method is based on the following chemical reaction [13]:

$$
\mathrm{MnO}_{4}{ }^{-}+5 \mathrm{Fe}^{2+}+8 \mathrm{H}^{+}=\mathrm{Mn}^{2+}+5 \mathrm{Fe}^{3+}+4 \mathrm{H}_{2} \mathrm{O}
$$

The $\mathrm{H}^{+}$needed for the above reaction is supplied by adding sulfuric acid and phosphoric acid to the reaction system.

The ferrous iron concentration (wt- $\%$ ), $\mathrm{X}_{2}$, in the PFS is determined from the expression:

$$
\mathrm{X}_{2}=\frac{\left(\mathrm{V}-\mathrm{V}_{0}\right) \times \mathrm{C} \times 0.05585}{\mathrm{~m}} \times 100 \times 5
$$

where $\mathrm{V}$ is the volume $(\mathrm{ml})$ of the potassium permanganate consumed by the PFS at the end point, $\mathrm{V}_{0}$ is the volume $(\mathrm{ml})$ of the standard potassium permanganate solution consumed by a blank (distilled water) at the end point, $\mathrm{C}$ is the concentration (M) of the standard potassium 
permanganate solution, $\mathrm{m}$ is the mass $(\mathrm{g})$ of the PFS sample, and 0.05585 is the mass $(\mathrm{g})$ of 0.001 mole iron.

\section{Determination of $B$ value}

The ratio of the mass of $\mathrm{OH}^{-}$to the mass of $\mathrm{Fe}^{3+}$ in the PFS is called the $\mathrm{B}$ value of the material. This quantity is determined by adding excess $\mathrm{HCl}$ to a sample and back titrating with sodium hydroxide.

The B value (wt-\%) of the PFS is calculated by the following expression:

$$
\mathrm{B}=\frac{\frac{\left(\mathrm{V}_{0}-\mathrm{V}\right) \times \mathrm{C} \times 0.0170}{17.0}}{\frac{\mathrm{m} \times\left(\mathrm{X}_{1}-\mathrm{X}_{2}\right)}{18.62}} \times 100
$$

where $\mathrm{V}_{0}$ is the volume $(\mathrm{ml})$ of standard sodium hydroxide titrant consumed by the blank (distilled water) sample at the end point, $\mathrm{V}$ is the volume $(\mathrm{ml})$ of standard sodium hydroxide titrant consumed by the PFS sample at the end point, $\mathrm{C}$ is the concentration (M) of the prepared standard sodium hydroxide solution, $\mathrm{m}$ is the mass ( $\mathrm{g}$ ) of the PFS sample, 0.017 is the mass (g) of $0.001 \mathrm{~mole}^{-}$, and 18.62 is mass (g) of $1 / 3$ mole iron.

A $1.500 \mathrm{~g}$ PFS sample accurate to $0.001 \mathrm{~g}$ is weighed and put into a $250 \mathrm{ml}$ Erlenmeyer flask. A $25.00 \mathrm{ml}$ portion of a $0.1 \mathrm{M}$ hydrochloric acid solution is pipetted into the flask and 20 $\mathrm{ml}$ cooled, boiled distilled water is then added. After being shaken for 2 minutes, the flask is covered with a watch glass and left to settle at room temperature for 100 minutes. Then $10 \mathrm{ml}$ prepared potassium fluoride solution $(500 \mathrm{~g} / \mathrm{L})$ and 5 drops of phenolphthalein indicator are added to the flask. The contents of the flask are titrated immediately with $0.0982 \mathrm{M}$ standard sodium hydroxide solution until the color in flask becomes faint red and does not fade in 30 seconds. When a blank test is performed, cooled, boiled distilled water is substituted for the PFS sample. 


\section{Determination of $\mathrm{pH}$}

A $1 \mathrm{~g}$ PFS sample is diluted with cooled, distilled water to exactly $100 \mathrm{ml}$ for the measurement of $\mathrm{pH}$ with an Orion Research Inc. model 250A pH meter. Orion Research Inc. model 9107BN electrodes are used and calibrated with Fisher potassium biphthalate buffer solutions ( $\mathrm{pH}=1,2$ and 3 at $20^{\circ} \mathrm{C}$, respectively).

\section{RESULTS AND DISCUSSIONS}

The methods of dosing sodium chlorate oxidant, including addition of all the sodium chlorate required stoichiometrically into reactor at the beginning of reaction and dosing the sodium chlorate over a period of time, have been examined. Originally, the total dose was simply put into the reactor initially with the ferrous sulfate and water. This was found to consistently leave some precipitate of yellow iron compounds at the bottom of the reactor after extended reaction periods. Analytical measurement showed the reducing ion concentration $\left(\mathrm{Fe}^{2+}\right)$ was well above the target concentration $(0.1 \mathrm{wt}-\%)$ as expected after reaction was finished. $\mathrm{SO}_{2}$ removal efficiency is high $(90-100 \%)$ at this reaction condition, which is shown in Figure 2. Subsequently the timer-pump dosing equipment was added to the system, allowing a pre-measured oxidant solution to be dosed into the reactor over several hours. Much better results were obtained, no yellow precipitated substance was formed and reducing ion concentrations in the resulting product was less than $0.1 \mathrm{wt}-\%$.

Effects of dosing rate of sodium chlorate on removal efficiency of sulfur dioxide from the inlet gas stream have been investigated, which are shown in Figure 3 and Figure 4. In both figures, typical removal efficiencies are in the range of $60-90 \%$. The more active oxidant there is in the reaction solution, the more efficiently sulfur dioxide is oxidized and removed from the gas 


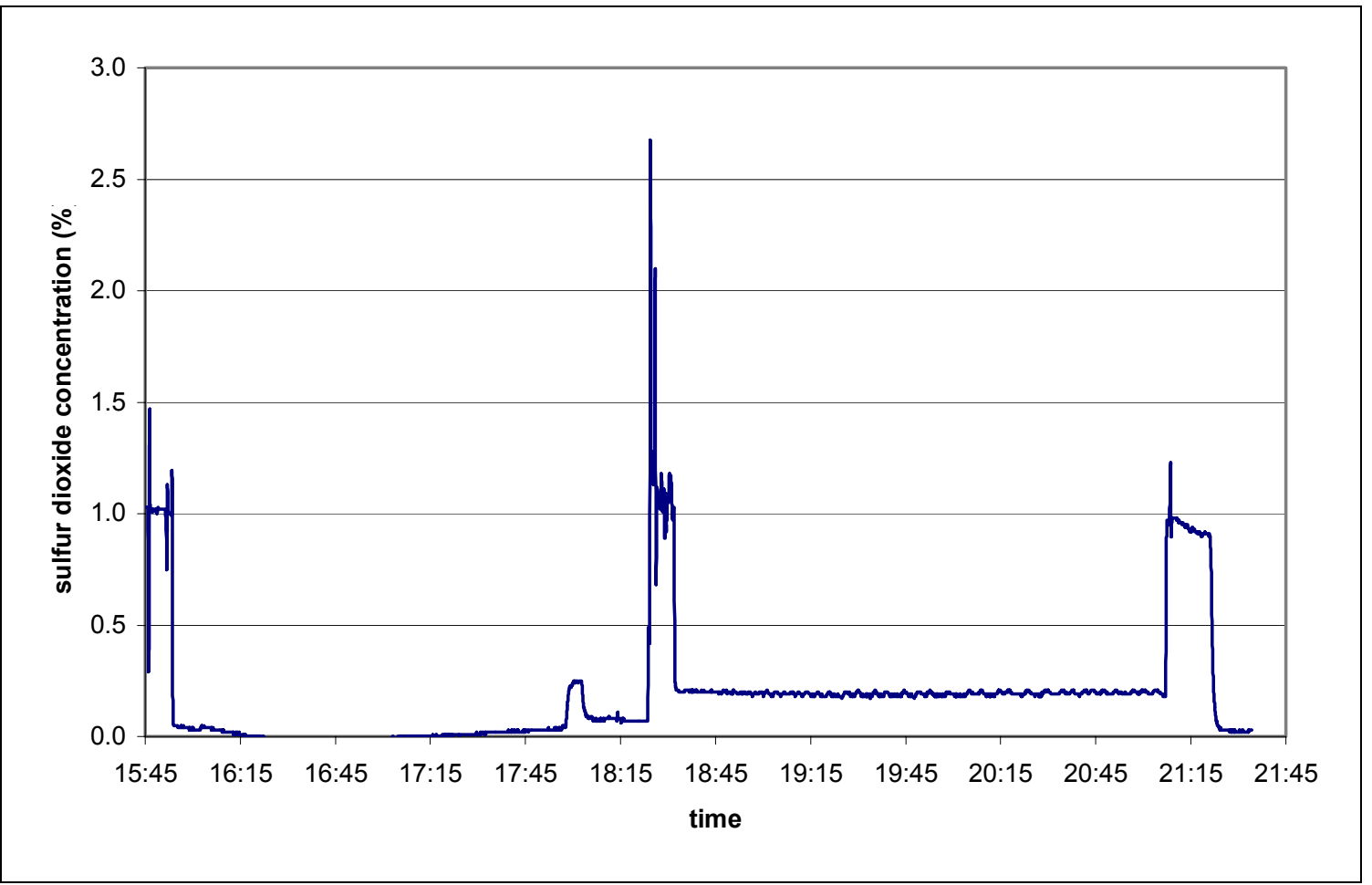

Fig. 2. Sulfur Dioxide Removal Test Batch 1. Reaction conditions: $127 \mathrm{~g}$ stoichiometerically needed sodium chlorate was dosed initially to reactor, total gas flow rate: $5 \mathrm{l} / \mathrm{min}, \mathrm{SO}_{2}$ inlet concentration: $1 \mathrm{v}-\%$ Temperature: $60^{\circ} \mathrm{c}$, and stirring speed: $180 \mathrm{rpm}$.

stream. Figures 3 and 4 show two different batches, with the same reaction conditions: 5 v- $\%$ inlet sulfur dioxide concentration, temperature $60{ }^{\circ} \mathrm{C}$, and stirring rate $180 \mathrm{rpm}$. In Figure 3 the sodium chlorate was dosed over approximately 5 hours, while in Figure 4 the duration was approximately 7.5 hours. The batch with more rapid oxidant dosage rate shows a removal efficiency centered around $80 \%$, while the other approaches only $60 \%$. The concentration spikes in Figures 3 and 4 are where the analyzer was switched to verify the inlet concentration of sulfur dioxide.

Thus far, preliminary quality tests of the products generated have shown that density, $\mathrm{Fe}^{2+}$ concentration and total iron concentration are satisfactory compared with the PFS standard in Table 1. However, $\mathrm{pH}$ and $\mathrm{B}$ values are not up to required standards. The measured $\mathrm{B}$ and $\mathrm{pH}$ 


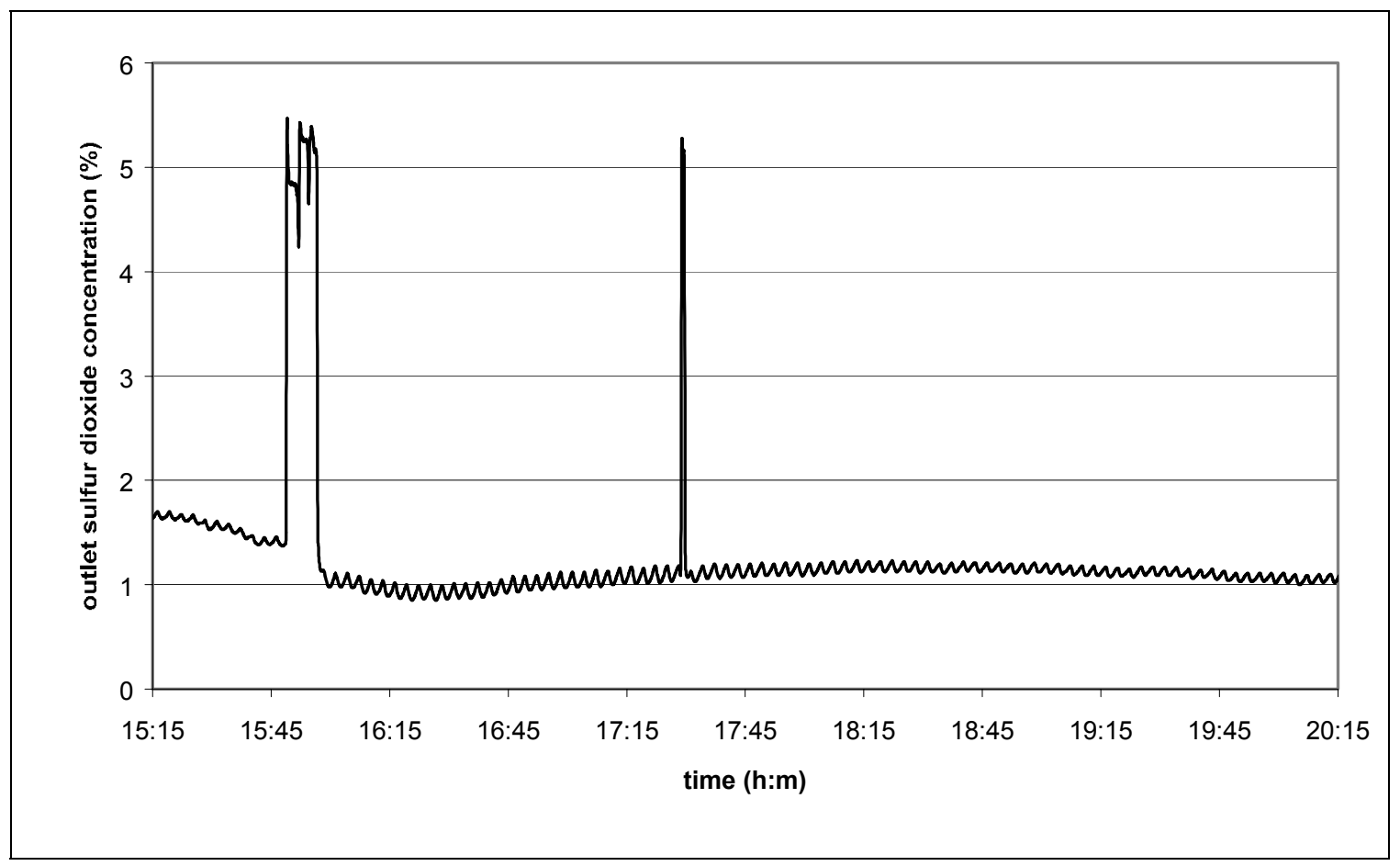

Fig. 3. Sulfur Dioxide Removal Test Batch 2. Reaction conditions: addition rate of sodium chlorate: $25.4 \mathrm{~g} / \mathrm{hr}$, total gas flow rate: $3 \mathrm{l} / \mathrm{min}, \mathrm{SO}_{2}$ inlet concentration: $5 \mathrm{v}-\%$, temperature: $60{ }^{\circ} \mathrm{C}$, and stirring speed: $180 \mathrm{rpm}$.

values are lower than the desired ranges. It is believed that this is due to over-addition of sulfur dioxide. Trials are currently being devised to verify this fact. Tests are currently underway to determine whether mass transfer controls the $\mathrm{SO}_{2}$ removal in this research. Initial trials involve sparging differing concentrations and flow rates of the simulated flue gas, maintaining constant the molar input rate of sulfur dioxide per time. A sample of reaction conditions is shown here in Table 2. Temperature, stirring rate, oxidizer dosing, and ferrous sulfate concentrations are all held constant among those trials. Results are still pending. 


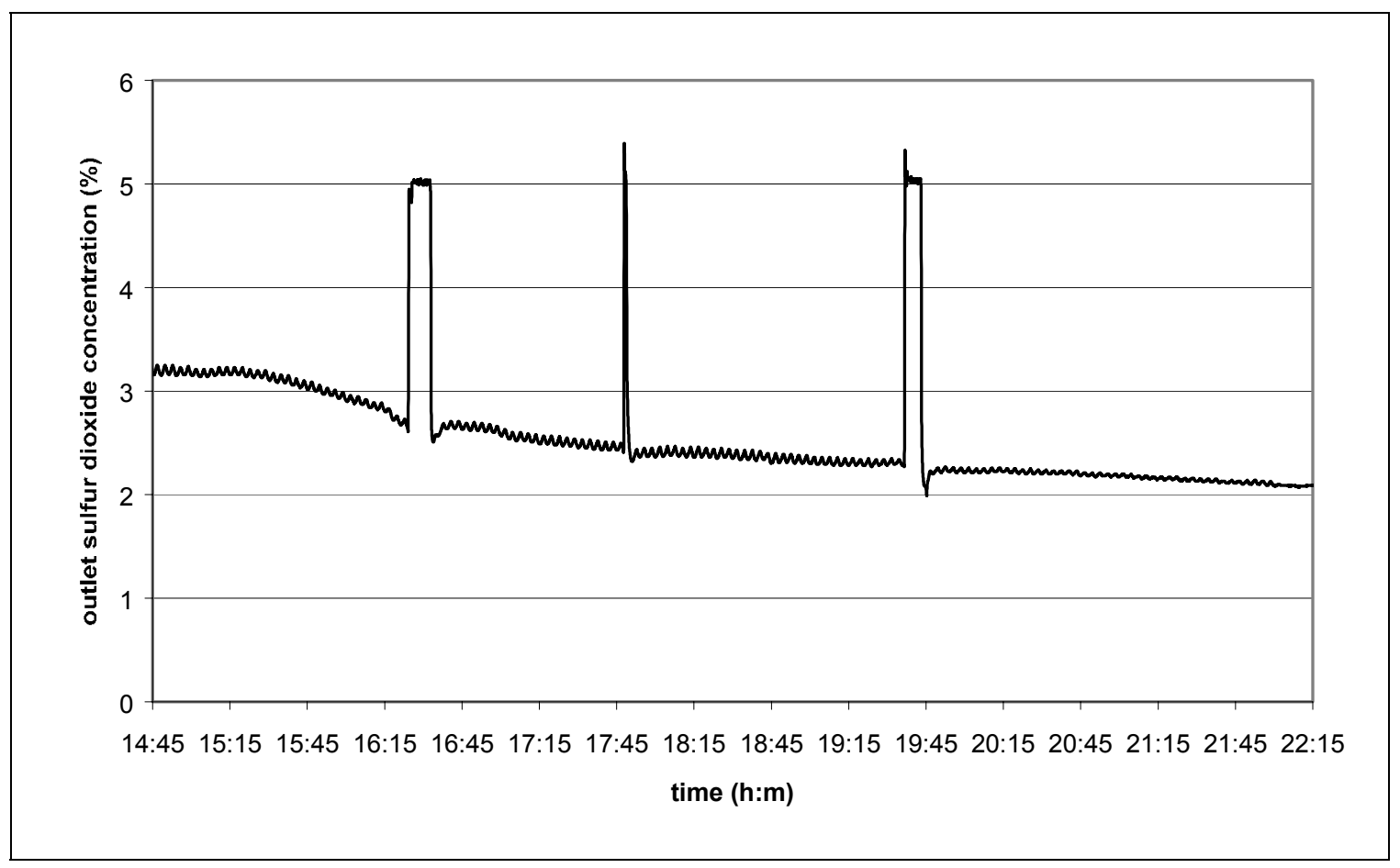

Fig. 4. Sulfur Dioxide Removal Test Batch 3. Reaction conditions: addition rate of sodium chlorate: $16.9 \mathrm{~g} / \mathrm{hr}$ : total gas flow rate: $3 \mathrm{l} / \mathrm{min}, \mathrm{SO}_{2}$ inlet concentration: $5 \mathrm{v-} \%$, temperature: $60^{\circ} \mathrm{c}$, and stirring speed: $180 \mathrm{rpm}$.

Table 2. Mass transfer trial conditions.

\begin{tabular}{cc}
\hline Sulfur dioxide concentration $($ vol- $\%)$ & Total gas flow rate $(1 / \mathrm{min})$ \\
\hline $2 \%$ & $51 / \mathrm{min}$ \\
$5 \%$ & $21 / \mathrm{min}$ \\
$10 \%$ & $11 / \mathrm{min}$ \\
\hline
\end{tabular}

\section{CONCLUSIONS}

Purchase and assembly of the experimental PFS synthesis system has been completed. PFS quality evaluation procedures have been established, and trials are underway. Preliminary results look promising, but a set of systemic tests and useful results are expected next year. Of 
the tasks outlined in the original project proposal, the following have been completed: Task 1 , literature search; Task 2, design and construction of reactor system for PFS synthesis; Task 3, establishment of PFS characterization techniques (quality tests). Task 4, determination of optimal conditions for conversion of sulfur dioxide to PFS, is currently underway. Task 5, development of a kinetic model of sulfur dioxide oxidation, Tasks 8, and 9, coagulation and sedimentation experiments as well as and filtration experiments on drinking water, are prepared to be underway early next spring. PFS samples from this process will be sent to the University of South Carolina for work on Task 8, as described in the proposal. Also, arrangements are being been made for a range of drinking water tests to be performed at the Des Moines Water Works upon completion of a pilot testing facility there next spring. This inventory of progress indicates that the work is on schedule with the timeline given in the proposal.

\section{REFERENCES}

1. Fan, M. (1993) A quick method for synthesizing highly efficient flocculant-polymeric ferric sulfate, Chinese Patent, ZL 931 20033.4.

2. Fan, M., Sung, S., Brown, R. C. Wheelock, T. D. and Laabs, F. C., (2002). Synthesis, Characterization and Coagulation of Polymeric Ferric Sulfate. Journal of Environmental Engineering, (accepted for publication)

3. Mikami, Y., Yanayi, M., Molita, H, and Tonaiyama, T (1980)., "The Manufacturing Method of Polymeric Ferric Sulfate Liquid." PPM., 5, 24-32, Tokyo, Japan (in Janpanese).

4. Mikami, Y. and Yanayi, M. (1984) “The Manufacturing Method of Polymeric Ferric Sulfate Liquid.” Japanese patent, No. 842085, Japan. 
5. Hendrich, S., Fan, M., Sung, S., Brown, R. C., Lebepe-Mazur, S., Myers, R \& Osweiler, G. (2002) Toxicity evaluation of polymeric ferric sulfate. International J. Water (accepted for publication).

6. National Research Council (1995) Coal: Energy for the Future, National Academy Press, Washington, D.C., pp. 2.

7. Yeh, J. T., Demski, R. J., Strakey, J. P., Joubert, J. I., (1985). Combined $\mathrm{SO}_{2} / \mathrm{NO}_{\mathrm{x}}$ Removal from Flue Gas. Detailed Discussion of a new Regenerable Fluidized-Bed Process Developed by the Pittsburgh Energy Technology Center. Environmental Progress 4(4), $223-8$.

8. Yeh, J. T., Hoffman, J. S., Pennline, H. W., (1993). Design of a Moving-Bed Copper Oxide Process for Simultaneous $\mathrm{SO}_{2}$ and $\mathrm{NO}_{\mathrm{x}}$ Removal. Presented at The A\&WMA 86th Annual Meeting \& Exhibition, June 14-18, 1993, Denver, CO.

9. Centi, G., Passarini, N., Perathoner, S., Riva, A., (1994b). Contemporaneous Removal of $\mathrm{SO}_{2}$ and NO from Flue Gas using a Regenerable Copper-on-Alumina Sorbent-Catalyst. ACS Symposium Series 552(Environmental Catalysis), 233-49.

10. Martyn, C.N., Coggan, D.N., Inskip, H., Lacey, R. F., and Young, W. F. (1997) Aluminum concentrations in drinking water and risk of Alzheimer's disease, Epidemiology, 8, pp. 281.

11. Truchet, M. (1995) Is aluminum a cause of Alzheimer's disease?, Canadian Medical Association Journal, 153 (6), pp. 741.

12. Chinese Administration of Chemical Engineering (CACE). (1992) “Chinese Polymeric Ferric Sulfate Quality Standard.” HG 2153-91, Beijing, China.

13. Peking University's Analytical Chemistry Experiment Manual. (1993). Beijing University, Beijing, China, 182-185. 


\section{APPENDIX. Standard Operating Procedures for PFS Synthesis System}

\section{Preparation for the Reaction}

Ensure that the hood fan is operating before starting the reaction. The green light only, indicating "normal" operation, must be illuminated.

Personal protective equipment (PPE) that must be worn during the operation of the reactor: Goggles, neoprene gloves, and lab coat.

Note: The chiller and RTE bath circulator are operated with a controller that is always on. The chiller is set to $2^{\circ} \mathrm{C}$ and the RTE to $60^{\circ} \mathrm{C}$. No adjustment is necessary unless the bath temperature needs to be raised or lowered for the reaction. For additional information on the operation of the controller, refer to the controller operations manual.

1. Turn on the $\mathrm{SO}_{2}$ analyzer with the switch on the left front of the unit. The analyzer requires at least 30 minutes to warm up.

2. Adjust temperature of the bath circulator by manipulating the directional arrows after pressing enter. After reaching the desired temperature, press enter twice on the front of the RTE. If further instructions are needed, refer to the RTE operations manual.

3. Put the oxidant solution, if required, into the flask in front of the peristaltic pump and insert the tubing for the pump into the flask. Insert the other end of the tubing, with adaptor, into the closest neck of the reactor lid. Clip on the adaptor with a 24/40 keck clip.

4. Ensure that the drain tube at the bottom of the vessel is closed.

5. Place the lid on top of the reactor and secure with the metal fastener.

6. Put $\mathrm{FeSO}_{4}$ or fly ash solutions into the vessel through a 24/40 neck opening.

7. Insert the stirrer into the large neck opening in the lid of the reactor and use a 45/50 keck clip to firmly attach the neck adaptor and stirrer to the lid. Plug in the stirrer to the wall 
socket in the hood. To adjust the speed of the stirrer, turn the knob on the top of the motor right or left as applicable, not to exceed 200rpm.

8. Insert a sparge tube into the left neck of the reactor lid and attach the tubing from the gas lines to the end of the sparge tube. Turn the screw of the metal fastener so it is firmly attached and does not leak. Fasten the neck adaptor containing the spurge tube to the lid of the reactor with a $24 / 40$ keck clip.

9. Insert the condenser to the back neck opening of the reactor lid and fasten with a 24/40 keck clip.

10. Insert a glass plug into the front neck opening of the reactor lid and fasten with a $24 / 40$ keck clip.

11. Turn the hand wheel on the breathing air gas cylinder to turn on the flow and adjust so the hissing through the Nafion drying tube is approximately 1-2 LPM.

12. Turn on the PC and enter the MS-DOS commands to collect data from the $\mathrm{SO}_{2}$ analyzer as outlined in the instruction sheet attached to the computer. At the prompt, type in SO2. The program will then ask for a filename and a reaction temperature $\left({ }^{\circ} \mathrm{C}\right)$. Enter appropriate responses.

\section{Conduct the Reaction}

During all the operations of the reactor, the pressure gauge on the inlet gas line must be monitored. Back-pressure buildup of less than 10 psig will ensure the successful and safe operation of the system. Pressure regulators on the cylinders should be adjusted to the output of no more than $10 \mathrm{psig}$. 


\section{$\mathrm{SO}_{2}$ Operations}

13. Turn the hand wheel on the $\mathrm{N}_{2}$ gas on. Adjust the associated flow meter to deliver $5 \mathrm{SCFH}$ $\mathrm{N}_{2}$.

14. Turn on the peri-pump and adjust knob or program on the control box to deliver required amount of oxidant. For further information of the programming of the peri-pump, or other attached equipment, refer to the controller operation manual.

15. Turn the hand wheel of the $\mathrm{SO}_{2}$ gas on. Adjust the associated flow meter to deliver the desired volume. The concentration can be verified by passing the inlet gas through the analyzer and is set by individual experimental design. The switch on the outlet gas line must be in the perpendicular position relative to the tubing.

16. Turn on outlet gas flow meter to enable the flow of outlet gas to the analyzer. To determine the percent concentration of $\mathrm{SO}_{2}$ in the outlet gas, the switch on the outlet gas line must be in the parallel position relative to the tubing.

17. For calibration instructions of the $\mathrm{SO}_{2}$ analyzer, refer to the manual.

\section{Shutdown the Reactor}

18. Turn off all of the gas cylinders. To attempt to remove the sulfur dioxide out of the system, turn off the cylinders in the following order: $\mathrm{SO}_{2}, \mathrm{~N}_{2}$, breathing air.

19. Turn off the peristaltic-pump by stopping the program on the controller or turning off the knob on the pump.

20. Stop the data collection program on the PC by pressing any button. Copy to a disk, if necessary. Turn off PC and monitor.

21. Turn off the $\mathrm{SO}_{2}$ analyzer with the switch on the front of the unit.

22. Unplug the stirrer from the wall outlet. 
23. Obtain a Nalgene container of appropriate size for the volume of product in the reaction vessel.

24. Insert drain tube at the bottom of the reactor into the top of the Nalgene container and turn the knob at the bottom of the reactor to open the drain. Let the product drain into the container. 